DOI: https://doi.org/10.3897/arb.v33.e01

\title{
DESCRIPTION OF THE "LIULIN TEN-KOH” CHARGED PARTICLES SPECTROMETER FOR THE JAPANESE “TEN-KOH” SATELLITE
}

\author{
Tsvetan Dachev ${ }^{1}$, Plamen Dimitrov ${ }^{1}$, Borislav Tomov ${ }^{1}$, Yuri Matviichuk ${ }^{1}$ \\ Premkumar Saganti ${ }^{2}$, Doug Holland ${ }^{3}$, Kei-Ichi Okuyama ${ }^{4}$, Isai Tapia ${ }^{4}$ \\ ${ }^{I}$ Space Research and Technology Institute - Bulgarian Academy of Sciences \\ ${ }^{2}$ Radiation Institute for Science and Engineering Prairie View A\&M University, Prairie \\ View, TX, USA \\ ${ }^{3}$ Holland-Space LLC, Houston, TX, USA \\ ${ }^{4}$ Kyushu Institute of Technology, Graduate School of Engineering, Kyushu, Japan \\ e-mail: tdachev@bas.bg
}

Keywords: Spectrometer, Charged Particle Detector, Liulin Ten-Koh

\begin{abstract}
On 29 October 2018 at 13:08 Japanese Standard Time was successfully launched the Greenhouse gas Observing SATellite (GOSAT-2) from the JAXA Tanegashima Space Centre. Piggyback with the GOSAT-2 satellite in a circular $(623 \mathrm{~km})$, polar synchronous orbit, was launched the 22 kilogram mass satellite Ten-Koh (http://kit-okuyama-lab.com/en/ten-koh/). It was developed in Kyushu Institute of Technology by Prof. K. Okuyama, Chief Scientist of the Spacecraft. Ten-Koh satellite is observing Low Earth Environment (LEO). The primary purpose is to provide valuable data for future development of satellites for operation. Ten-Koh's primary science instrument is the Charged Particle Detector (CPD) developed at the Prairie View A\&M University, and NASA Johnson's Space Centre of Houston, TX, USA. Principal Scientist of this payload is Prof. P. Saganti (https://www.pvamu.edu/raise/space-payload/charged-particle-detector-2018/). Principal Engineer of the CPD project is S. D. Holland (formerly with NASA-JSC and currently with Holland-Space LLC, Houston, TX, USA). SRTI-BAS received a request from Prof. Saganti to develop a Liulin type instrument to be part of the CPD payload. Scientists from SRTI's Solar-Terrestrial Physics Department have developed and handed three units per request (engineering, flight, and operational models) of the instrument named "Liulin Ten-Koh". These instruments are similar to the RADOM instrument, which worked in 2008-2009 on the Indian Moon satellite Chadrayaan-1 [12]. This paper describes the flight model, "Liulin Ten-Koh Saganti" instrument and standard sources radiation tests, which were performed during the calibrations in the laboratory of SRTI-BAS. As of this writing, Ten-Koh spacecraft is making a polar orbit passes as expected at about $623 \mathrm{~km}$ altitude and at 98 degree inclination with healthy telemetry data as received by several ground stations across the world. The first received data from "Liulin Ten-Koh Saganti" instrument of the Ten-Koh spacecraft are presented. The available at this moment Galactic Cosmic Rays (GCR) L-value profiles of the dose rate and the dose to flux ratio $(D / F)$ from 11 December 2018 are compared with the R3DE profile at the International Space Station (ISS). Additionally, the integral "Liulin Ten-Koh Saganti" instrument LET spectrum from 11 December 2018 is compared with spectra from other instruments, measured in and out of the Earth magnetosphere.
\end{abstract}




\section{Introduction and "Liulin Ten-Koh" instrument description}

The most notable difference between occupational radiation exposures that occur on Earth and those in space is that astronauts experience a persistent low background field of radiations of mixed biological effectiveness, including energetic electrons, high-energy heavy-ion component of galactic cosmic rays (GCR), secondary neutrons, and densely ionising low-energy secondary ions and energy-degraded primary ions [1].

The major risk of space travel is cancer from GCR, while circulatory diseases in suggested in some but not all epidemiology studies at modest doses $(<1 \mathrm{~Gy})$ and detriments in cognition are suggested by rodent studies following acute irradiation with moderate doses of heavy ions. The GCR are not easily shielded since they consist of high-energy protons, heavy ions and secondary radiation produced in shielding and tissue. Furthermore, heavy ions are more effective per unit dose in causing solid cancers compared to gamma rays. Additionally, non-targeted effects (NTEs) are suggested by most low dose radiobiology studies to increase the biological effectiveness for low doses of high linear energy transfer (LET) radiation [2]. Therefore, precise measurements of radiation sources doses and their distribution in the low earth orbits (LEO) are of great importance.

The "Liulin Ten-Koh" instrument is a Liulin-type deposited energy spectrometer (DES) instrument, which was successfully flown: (1) in the US Laboratory module of the ISS in May-August 1991 [3-9]; (2) inside ESA Biopan5/6 facilities on Foton M2/M3 satellites [10-11]; (3) Indian Chandrayaan-1 satellite [12] and (4) in-side the ESA EXPOSE-E/R/R2 facilities outside the Columbus/Zvezda modules of the ISS in 2008-2016 [13-15].

Fig. 1 shows the external view of the 3 "Liulin Ten-Koh" instruments. The first picture to the left presents the technological model "Liulin Ten-Koh". In the middle is the flight model ("Liulin Ten-Koh Saganti", while the spare model ("Liulin Ten-Koh Saganti 2F", is at the right side of the figure. With the instruments are shown the necessary for laboratory use with computer external power supplies, RS-232 bridges and cables.

The "Liulin Ten-Koh" spectrometer main purpose is to measure the spectrum (in 256 channels) of the deposited energy from primary and secondary particles in the Ten-Koh satellite radiation environment.

The "Liulin Ten-Koh" spectrometer is designed as spectrometer-dosimeter for continuous monitoring of the satellite radiation environment, which can consist of GCR particle, Inner radiation belt (IRB) protons, outer radiation belt (ORB) relativistic electrons and energetic protons from solar origin (SEP). The last sources selection procedure was developed and published recently in [15]. 

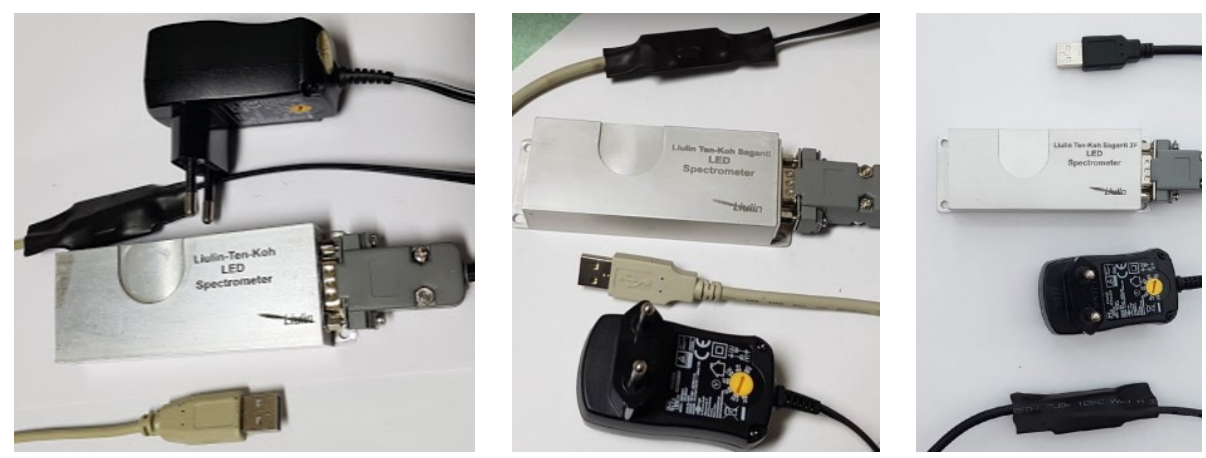

Fig. 1. External view of the 3 "Liulin Ten-Koh" instruments. The instruments are presented with the necessary: external power supply, RS-232 bridges and cables.

After switching on, the "Liulin Ten-Koh" spectrometer performs internal test and wait to obtain external command. On a receipt of command, it starts to accumulate in 256 channels the spectrum of the deposited energy used further to calculate the dose and flux of particles in the silicon detector. The exposition time of one spectrum depends on the frequency of the external command issue to measure and can be between 5 and $2100 \mathrm{sec}$ with $1 \mathrm{sec}$ resolution.

The "Liulin Ten-Koh" spectrometer contains: one semiconductor detector silicon PIN diode of Hamamatsu S2744-08 type with $2 \mathrm{~cm}^{2}$ in area and $0.3 \mathrm{~mm}$ thickness, one low noise hybrid charge-sensitive preamplifier A225F type of AMPTEK Inc., a fast 12 channel ADC, 2 microcontrollers and buffer memory. The pulse high analysis technique is used for measurement of the energy losses in the detector through specially developed firmware. A block schema of "Liulin TenKoh" portable spectrometer-dosimeter is presented in Fig. 2.

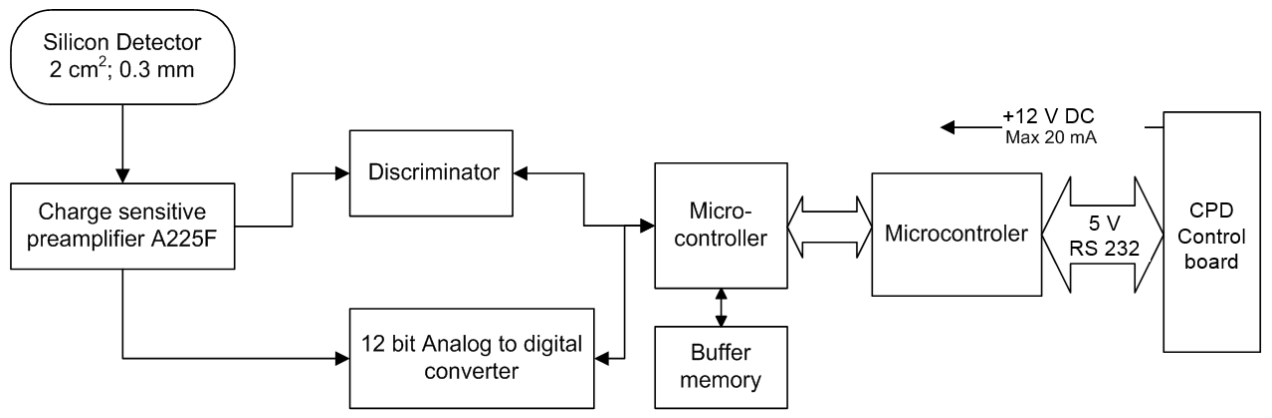

Fig. 2. Block-scheme of the "Liulin Ten-Koh" spectrometer 
The main measurement unit in the "Liulin Ten-Koh" instrument is the amplitude of the pulse after the preamplifier, generated by particles or quanta, hitting the detector [3]. The amplitude of the pulse is proportional to a factor of 240 $\mathrm{mV} \mathrm{MeV}^{-1}$ to the energy loss in the detector and, respectively, to the dose. By 12bit analogue to digital converter (ADC) these amplitudes are digitised and organised in a 256-channel deposited energy spectrum. The dose in the silicon detector $\mathrm{D}_{\mathrm{Si}}[\mathrm{Gy}]$ by definition in System international (SI) is one Joule deposited in a $1-\mathrm{kg}$ matter. The absorbed dose is calculated by dividing the summarised in 256 channels energy depositions in the spectrum in Joules to the mass of the detector in kilogrammes.

The semiconductor detector of the "Liulin Ten-Koh" instrument is mounted approximately $2 \mathrm{~mm}$ below the $0.3 \mathrm{~mm}$ thick aluminium cover plate. Furthermore, there is shielding from $0.07 \mathrm{~mm}$ copper and $0.2 \mathrm{~mm}$ plastic, which provided $0.3 \mathrm{~g}$ $\mathrm{cm}^{-2}$ of total shielding from the front side. The "Liulin Ten-Koh" instrument is additionally shielded by 2 FR-4 (glass epoxy) plates with a total thickness of $3.15 \mathrm{~mm}$ and by $5.0 \mathrm{~mm}$ carbon fiber reinforced polymer (CFRP) The calculated required kinetic energy of particles penetrating all the shielding's perpendicular to the detector is $2.6 \mathrm{MeV}$ for electrons and $62.5 \mathrm{MeV}$ for protons (https://physics. nist.gov/PhysRefData/Star/Text/PSTAR.html). The obtained kinetic energy values are approximatively because in the cited above tables are not listed exactly the FR4 and CFRP materials.

This means that only electrons and protons with energies exceeding the values listed above can cross the "Ten-Koh" satellite and "Liulin Ten-Koh" instrument shielding materials and reach the detector surface. The detector shielding, being larger from the sides and from behind, stops less energetic ORB relativistic electrons, attenuates the lover energy IRB and SEP protons, but does not change the flux of the primary GCR particles.

\section{The Charged Particle Detector (CPD) and the "Ten-Koh" satellite}

The "Liulin Ten-Koh" instrument is mounted on the top (Fig. 3) of the Charged Particle Detector (CPD) developed at the Prairie View A\&M University, and NASA Johnson's Space Centre of Houston, TX, USA. Principal Scientist of this payload is Prof. P. Saganti (https://www.pvamu.edu/raise/spacepayload/charged-particle-detector-2018/). Principal Engineer of the CPD project is S. D. Holland (formerly with NASA-JSC and currently with Holland-Space LLC, Houston, TX, USA (www.holland-space.com).

The CPD manages the measurements with the following sensors: Liulin Spectrometer, 2 Open Sensors for Ambient Radiation Measurements, 2 Polyethylene Covered Sensors for Shielding Assessment, 2 Polyethylene Covered Sensors for Skin Dose Assessment, 2 X-ray Detectors. CPD also communication with In-Flight programing capacity with "Ten-Koh" satellite (Fig. 3). 


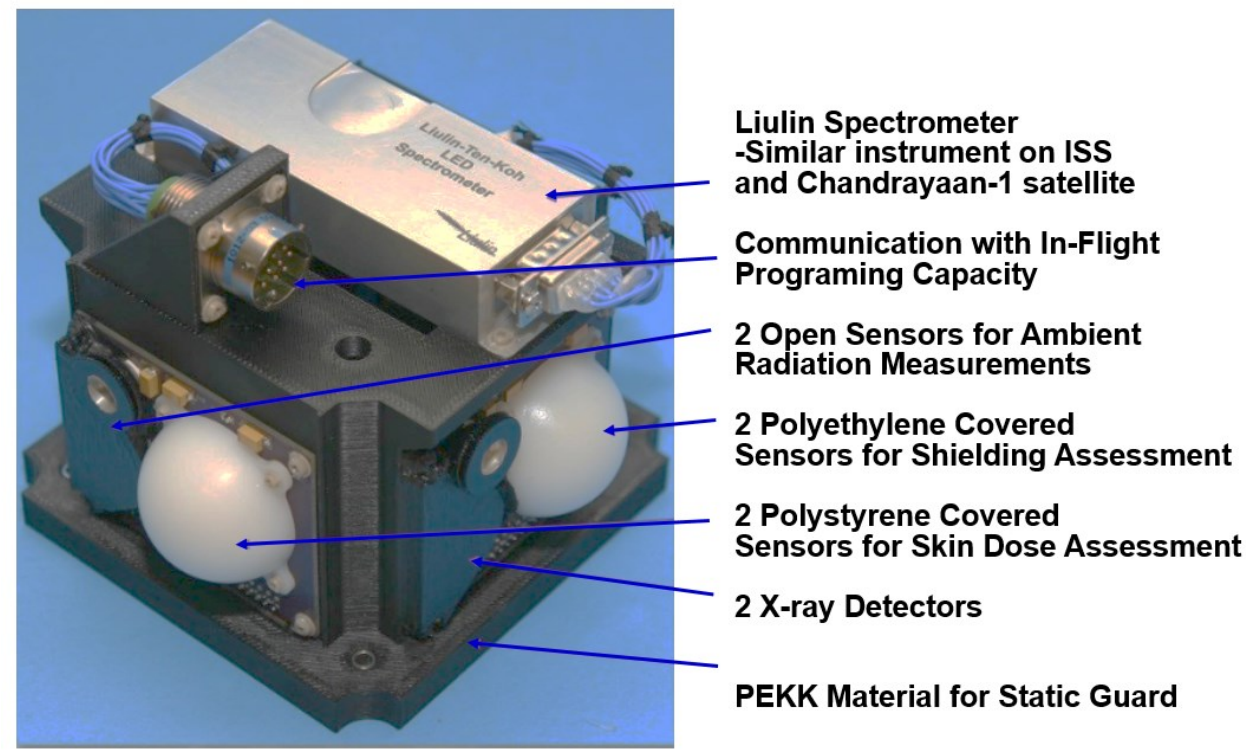

Fig. 3. The CPD with mounted above "Liulin Ten-Koh" instrument

The Ten-Koh satellite was developed at Kyushu Institute of Technology by Prof. K. Okuyama, Chief Scientist (http://kit-okuyama-lab.com/en/ten-koh/). The satellite shape is quasi-spherical (Fig. 4), which diameter is about $500 \mathrm{~mm}$ and surrounded by solar cells. This satellite is constituted of structure, thermal control, attitude control, telecommunication, Bus power system and payload power system. The exact sizes are $\mathrm{H} 465 \times \mathrm{W} 500 \times \mathrm{D} 500 \mathrm{~mm}$ and the mass is about $22.0 \mathrm{~kg}$. The Ten-Koh satellite houses the CPD behind the top solar panel and 2 FR-4 plates.

The first purpose of the Ten-Koh satellite missions is to observe LEO environment and initial unveiling of the data. Recently, as the development of microsatellites by universities and other institutes has become active, breakdowns of them on LEO $2000 \mathrm{~km}$ below have often occurred. Most of these causes are cosmic radiation, which has various energy levels and come from the ORB and Sun. To prevent these breakdowns, the "Ten-Koh will measure various LEO environment parameters and unveil the data via the internet initially. The second purpose of the Ten-Koh satellite is to measure the degradation of advanced material, which can use in the future. 


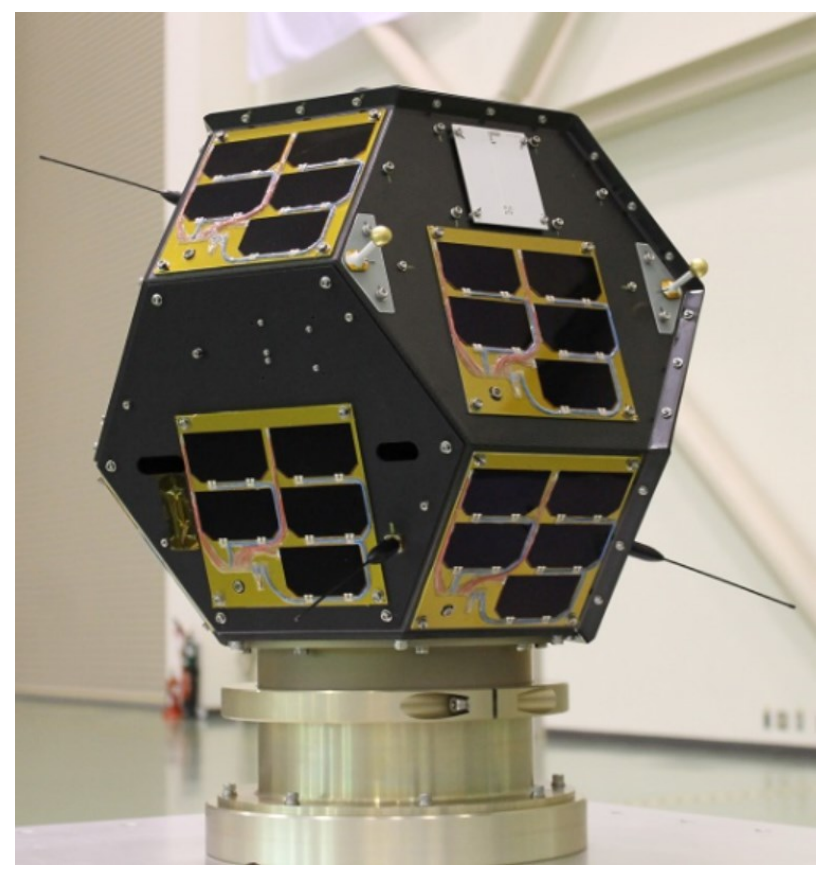

Fig. 4. The "Ten-Koh" satellite

On 29 October 2018 at 13:08 Japanese Standard Time was successfully launched the Greenhouse Gas Observing SATellite (GOSAT-2) from the JAXA Tanegashima Space Centre. Piggy-pack with the GOSAT-2 satellite in a circular $(623 \mathrm{~km})$, polar synchronous orbit was launched the "Ten-Koh" satellite.

\section{The "Liulin-Ten-Koh 2.exe" software product}

The "Liulin-Ten-Koh 2.exe" software product is used for managing the "Liulin-Ten-Koh" spectrometer and for express analysis of the results when is used directly with PC in laboratory tests and measurements. The software includes subprograms for data listing and data visualisations.

The "Liulin-Ten-Koh 2.exe" software was developed in the Windows environment. The purpose of the software is to manage the Liulin spectrometer performance and to analyse and visualise the data during the laboratory tests. At the PC it automatically creates the subdirectory "Data" in the directory in which "Liulin-Ten-Koh.exe" is located. In the subdirectory, "Data" one binary file with extension "LTF" is automatically created at the end of measurements when reading the data from "Liulin-Ten-Koh 2.exe" is performed. The binary file of "Liulin TenKoh Saganti 2F" instrument is named automatically and contains in the name the string "YYMMDDhhmm". The extension of the binary file is "LTF". 
"YYMMDDhhmm" is the date and time of the moment when the measurements begin. This file contains the rough binary data and is for permanent storage of data from the instrument because it is with minimal volume. Three ASCII files are automatically created in the same subdirectory "Data", from the binary file, when "Select HEX data" button in "Liulin-Ten-Koh 2.exe" is activated. The names of the ASCII files contain the same "YYMMDDhhmm" string as the binary file. For example, the ASCII files with extensions of type "d2F", "s2F", and "y2F" contain the "D"ose, "S"pectrum, "Y" (pure spectrum) data, respectively, from the Liulin Ten-Koh Saganti 2F instrument.

\section{Standard radiation sources tests and calibrations}

The calibration procedures, which were performed using analogical to "Liulin Ten-Koh" instruments, are described in [2,9 and 15]. The response curve of the "Liulin Ten-Koh" instrument is expected to be similar to that published by Uchihori et al. (2002) [16] because all Liulin DES instruments were manufactured using the same electronic parts and schematic. In a specific example [16] of the calibration was performed by Dr. Yukio Uchihori, it was found that the linear coefficient of the response curve, obtained during the calibrations with protons, $\mathrm{He}^{+}$and $\mathrm{Ne}^{+}$ions, was equal to $81.3 \mathrm{keV}$, whereas the Liulin DES instruments predicted value was $81.4 \mathrm{keV}$.

The first procedure during the calibration process of the "Liulin Ten-Koh Saganti" instrument in the laboratory of IKIT-BAS was to adjust the position of the first spectrometric channel using the ${ }^{241} \mathrm{Am} 60 \mathrm{keV}$ gamma line. Furthermore, the linearity is controlled by electronic methods, as described by AMPTEK INC. In the A225 preamplifier-operating notes (http://www.amptek.com/pdf/a225.pdf).

Fig. 5 was obtained during the tests of 'Liulin-Ten-Koh Saganti" (flight) instrument in the SRTI-BAS laboratory on 12/02/2018. The exposition time is $15 \mathrm{sec}$. The dose curve is with red points and lines, while the flux curve is with blue points and lines. The low doses in the left, middle and right part of the picture correspond to natural background radiation that is why the calculated average dose between the two vertical lines in the centre of Fig. 5 is $0.1296 \mu \mathrm{Gy} \mathrm{h}{ }^{-1}$. This value is close to the natural background radiation but a little higher because of small exposition time and, respectively, small statistics. The first stage (step) in doses and fluxes in Fig. 5 was generated using $60 \mathrm{keV}$ gamma line from ${ }^{241} \mathrm{Am}$ source, while the second one corresponds to much higher doses $\left(\sim 300 \mu \mathrm{Gy} \mathrm{h} \mathrm{h}^{-1}\right)$ and fluxes $\left(120 \mathrm{~cm}^{-2} \mathrm{~s}^{-1}\right)$ generated by ${ }^{137} \mathrm{Cs}$ source. The calibrations with ${ }^{137} \mathrm{Cs}$ source are the second procedure in the calibration process, which shows that the instrument works stable at high count and dose rates expected in space. 


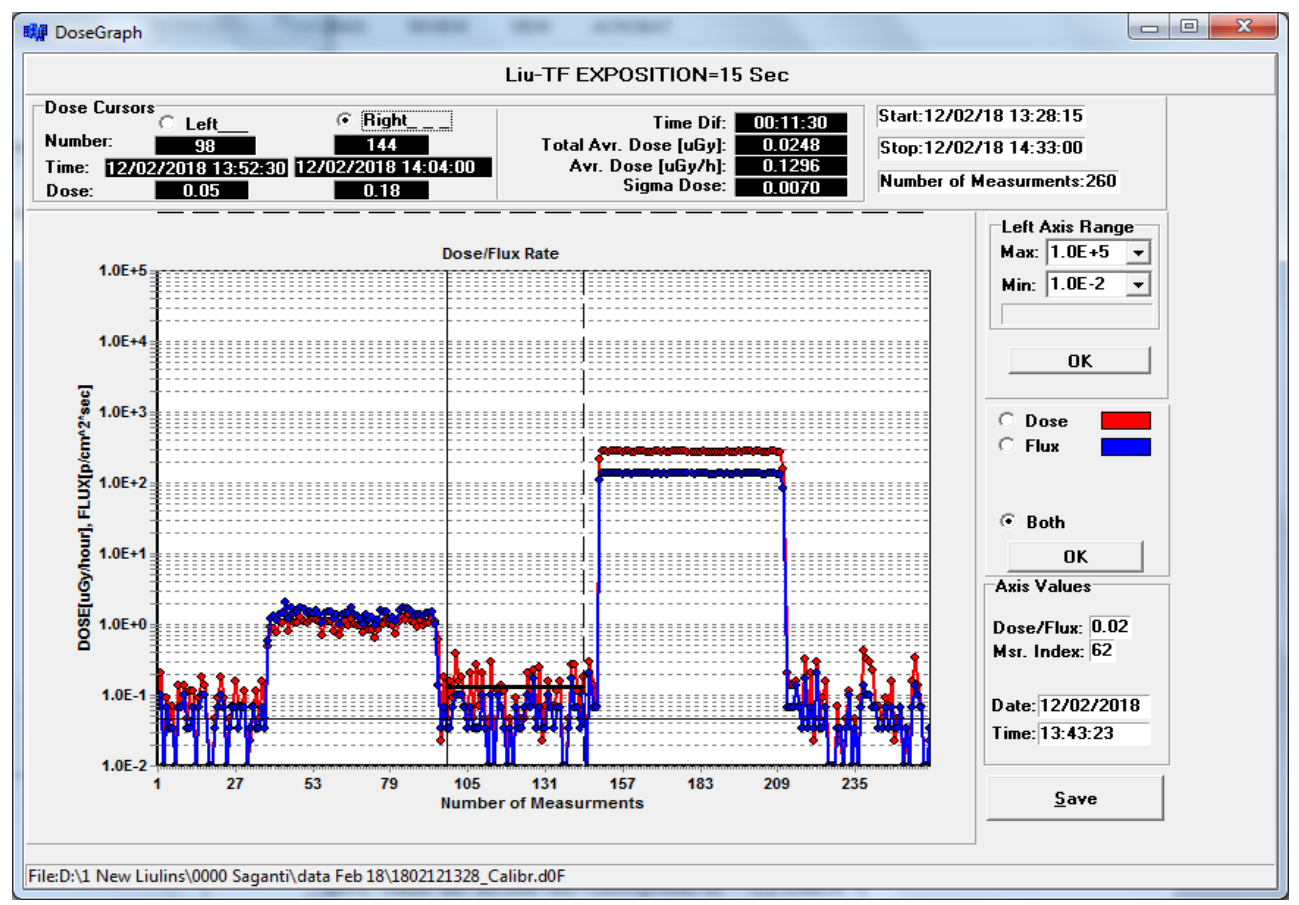

Fig. 5. Calibrations with ${ }^{241} \mathrm{Am}$ and ${ }^{137} \mathrm{Cs}$ sources

Fig. 6 is the colour-coded Energy/Time diagram of the same tests as in Fig. 5 of "Liulin Ten-Koh Saganti". It is well seen in the upper panel of Fig. 6 that the ${ }^{241} \mathrm{Am} 60 \mathrm{keV}$ gamma line source produces high-count rate only in the first channel of the "Liulin Ten-Koh Saganti" spectrometer what is expected because the energy loss in this channel is between 40 and $120 \mathrm{keV}$. The ${ }^{137} \mathrm{Cs}$ source produces a wider spectrum (up to 10th channel) with a maximum count rate in the second channel. In the lover panel of Fig. 6 the sum of the events in each spectra is displayed.

The last procedure during the calibration process is long-term background measurements, which must contain events with high-energy depositions in high channel number depositing high dose rates. The latter confirm whole calibration process and the ability of the instrument to work in real space conditions 


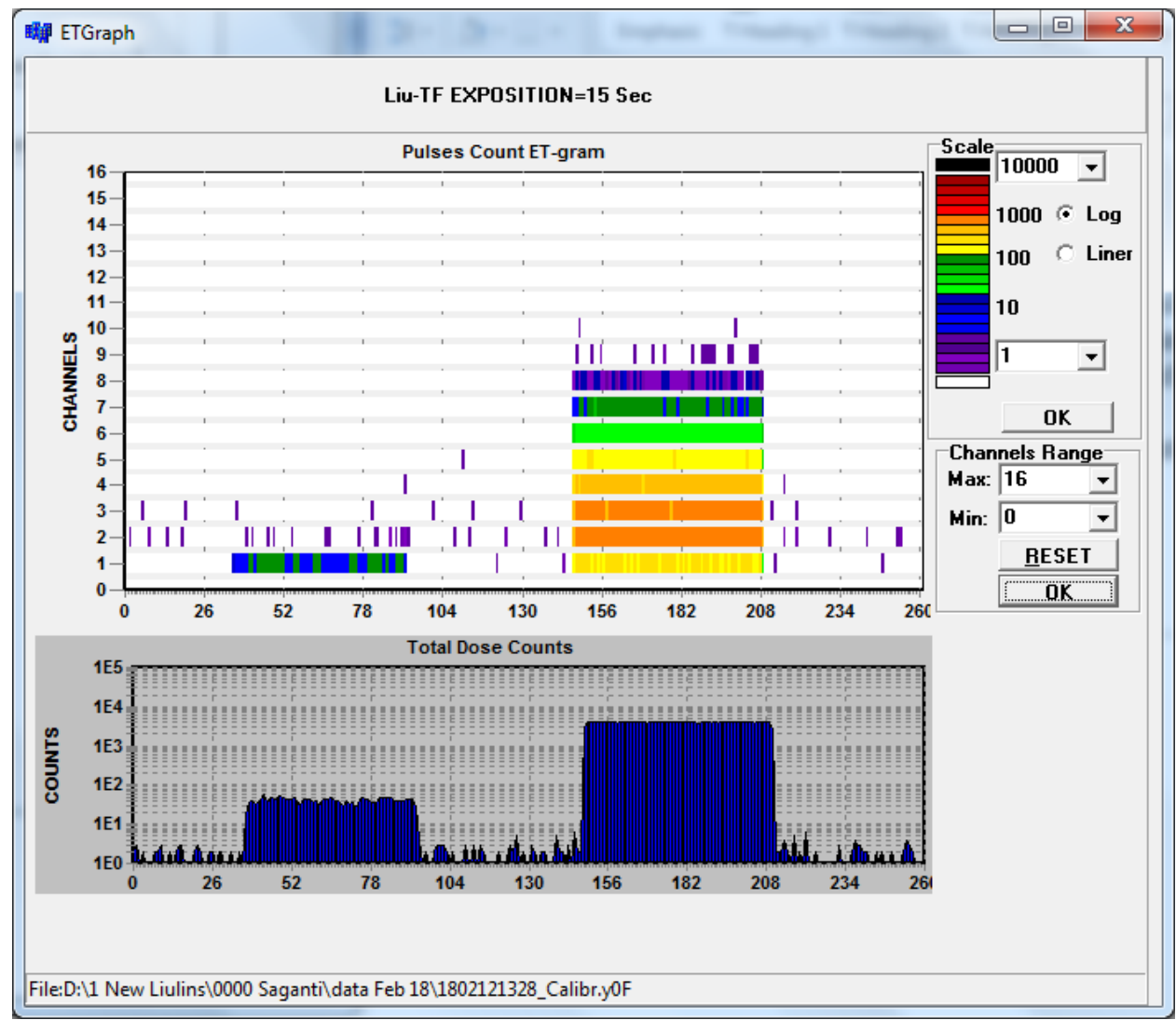

Fig. 6. Same as in Fig. 5 but colour-coded

Fig. 7 shows the dose/flux graphic obtained from the long-term measurements performed using "Liulin Ten-Koh Saganti" instrument. It is seen that the start was on 09/02/18 at 19:04:00 LT. 485 measurements with 300 seconds exposition were performed and the stop time was on 11/02/18 at 11:24:00 LT. This information is automatically calculated by the software and presented in the black filled table cells in the right part of Fig. 7. From the right part black filled table cells, it is seen that for 40:20:00 hours the total dose is 4.9752 $\mu \mathrm{Gy}$, while the average dose rate is $0.1234 \mu \mathrm{Gy} \mathrm{h}^{-1}$. Sigma of the dose is 0.0006 . Very high dose events are seen in the left-hand part of Fig. 7. The highest dose rate is $\sim 0.42 \mu \mathrm{Gy} \mathrm{h}^{-1}$ seen in magenta circles of Fig. 7 . 


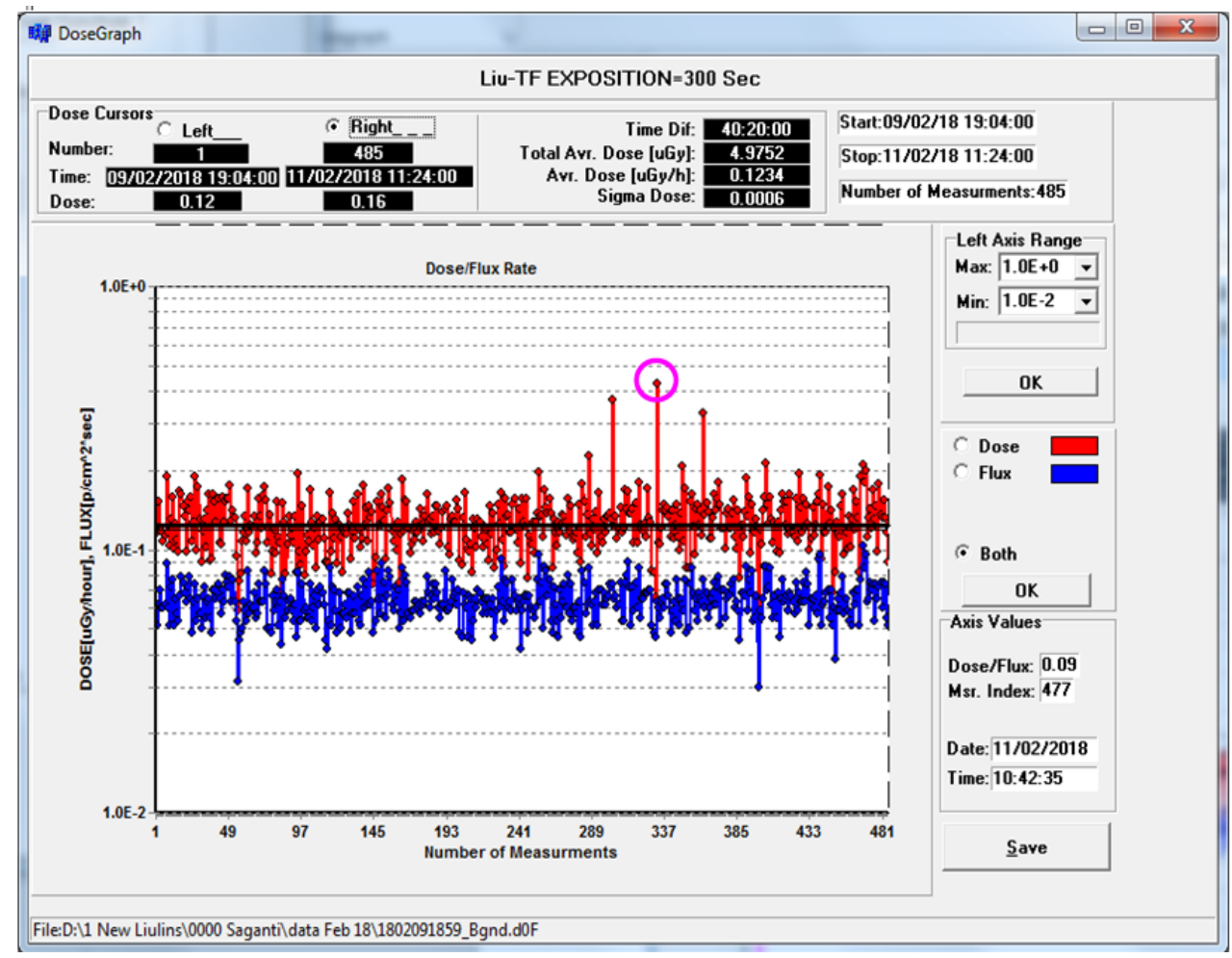

Fig. 7. Long-term background measurements

Fig. 8 shows the spectrum graphic obtained from the long-term measurements performed using "Liulin Ten-Koh Saganti" instrument. The red points present the separate counts in each channel from 1 to 256, while the blue points and line present the summarised number of counts in each channel. It is seen that the major number of points are distributed normally in the channel range from 1 to 16 with maximum counts in the $2^{\text {nd }}$ channel. Accidentally, high-energy (dose) depositions are observed in channel numbers of the spectrometer around 146th, 206th and 256th channels (Emphasized with the magenta circle.). These highenergy depositions once again confirm that the "Liulin Ten-Koh Saganti" spectrometer covers the whole energy range. 


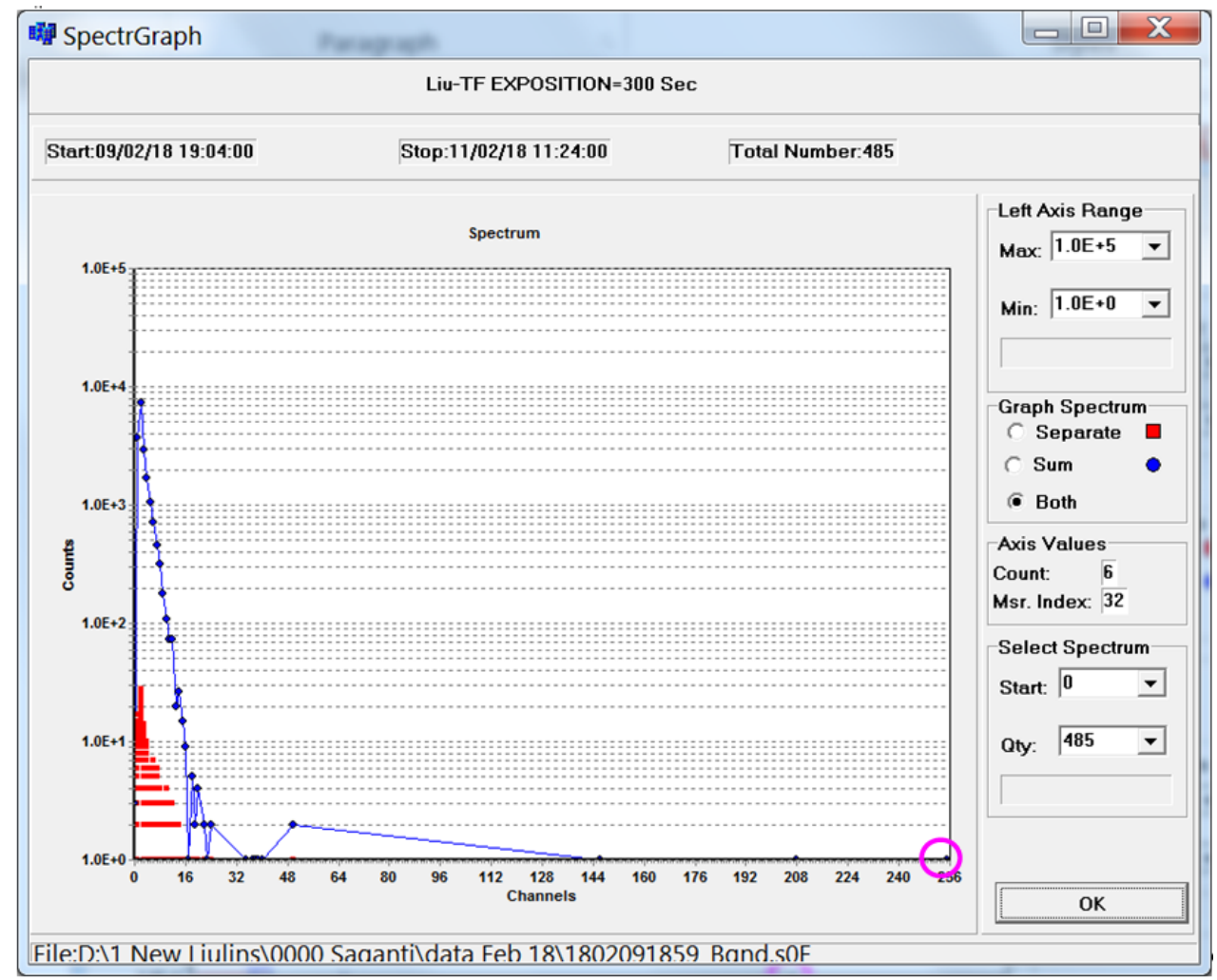

Fig. 8. The obtained spectrum during the long-term background measurements

\section{Analysis of the first data obtained from "Liulin Ten-Koh Saganti" instrument}

The first command transmission and data downlink with Ten-Koh satellite happen over KIT, Japan on 31 Oct 2018. The first "Liulin Ten-Koh Saganti" spectrum was received on 08 November 2018 at 13:17:00 Japanese Standard Time. The full number of 5 measurements is presented in Table 1 .

From Table 1 it is seen that the "Liulin Ten-Koh Saganti" average dose rate is $1.72 \mu \mathrm{Gy} \mathrm{h} \mathrm{h}^{-1}$, while the average flux is $0.28 \mathrm{~cm}^{-2} \mathrm{~s}^{-1}$. The values are typical for GCR at low latitude $\sim 34^{\circ} \mathrm{N}$ at the longitude of about $\sim 140^{\circ} \mathrm{E}$. To confirm these values, we take data from the R3DR2 instrument on the ISS in the time interval 21-30 June 2015. The GCR L-value profile for this time interval can be seen at Fig $3 \mathrm{~b}$ of [15]. The obtained R3DR2 average dose rate and flux values from 46 points inside a rectangular area with coordinates between $139^{\circ}$ and $141^{\circ}$ geographic longitude and between $30^{\circ}$ and $40^{\circ}$ geographic latitude are $1.57 \mu \mathrm{Gy} \mathrm{h}^{-1}$ and 
$0.45 \mathrm{~cm}^{-2} \mathrm{~s}^{-1}$. These values are close to the "Liulin Ten-Koh Saganti" values and confirms our expectations that GCR particles are registered.

Table 1

\begin{tabular}{|c|c|c|c|c|}
\hline Day/Time & $\begin{array}{c}\text { Exposition } \\
{[\mathrm{sec}]}\end{array}$ & Counts & Flux $\left[\mathrm{cm}^{-2} \mathrm{~s}^{-1}\right]$ & $\begin{array}{c}\text { Dose rate } \\
{\left[\square \mathrm{Gy} \mathrm{h}^{-1}\right]}\end{array}$ \\
\hline $08 / 11 / 201813: 17: 00$ & 15.286 & 10 & 0.33 & 2.13 \\
\hline $12 / 11 / 201813: 59: 00$ & 15.286 & 11 & 0.39 & 2.35 \\
\hline $12 / 11 / 2018$ & 15.286 & 6 & 0.19 & 0.39 \\
\hline $18 / 11 / 201813: 33: 53$ & 15.286 & 8 & 0.26 & 2.79 \\
\hline $18 / 11 / 2018$ & 15.286 & 7 & 0.23 & 0.92 \\
\hline Aver. (Liulin Ten-Koh) & & & $\mathbf{0 . 2 8}$ & $\mathbf{1 . 7 2}$ \\
\hline Aver. (R3DR2) & & & $\mathbf{0 . 4 6}$ & $\mathbf{1 . 5 7}$ \\
\hline
\end{tabular}

The number of 9 "Liulin Ten-Koh Saganti" spectra was received on 11 December 2018. The date, time and geographic coordinates of Ten-Koh satellite normal mode execution is characterised by Mission starting time: 09:02:31 JST (11-12-2018 00:02:31 UTC) and mission-ending time: 09:07:05 JST (11-12-2018 00:07:05 UTC); The starting latitude is $47.3239^{\circ} \mathrm{N}$, while the starting longitude is $6.3512^{\circ} \mathrm{W}$.

Keeping in mind the amount of more than $2 \mathrm{MeV}$ energetic electron flux in the L-shell plot from the MagEIS instrument aboard the Van Allen Probes (https://www.swpc.noaa.gov/products/van-allen-probes-radiation-belt-plots) for $11^{\text {th }}$ December 2018 our first concern was to establish in the best way the type of predominant radiation source (GCR particles or outer radiation belt (ORB) relativistic electrons) measured. Recently, in [15] it was shown that the best analysis of the radiation source type could be made from the deposited energy spectrum shape.

Figure 9 illustrates the different shapes of the deposited energy spectra (GCR, IRB, ORB and SEP) as obtained from the R3DR2 instrument from 21 to 30 June 2015 (data seen in figures 3a and 4 of [15]). The deposited dose rate is the area between the abscissa and the curve of the deposited energy spectrum. The "GCR" and "IRB," spectra obtained in the period 21-30 June 2015 is shown in Figure 9 only to validate the R3DR2 data spectrum shapes against those described in [17] that are why we will not analyse them further. The "ORB" spectrum is clearly divided into 2 parts. The low-energy part up to $2 \mathrm{MeV}$ deposited energy is populated by relativistic electrons from ORB, while the high-energy part up to $20.83 \mathrm{MeV}$ is populated by GCR particles, observed at high latitude region. Therefore, this part of the spectrum looks similar to the GCR spectrum but elevated to higher values because smaller geomagnetic shielding. (Please, read more in the Fig. 10-description.) 


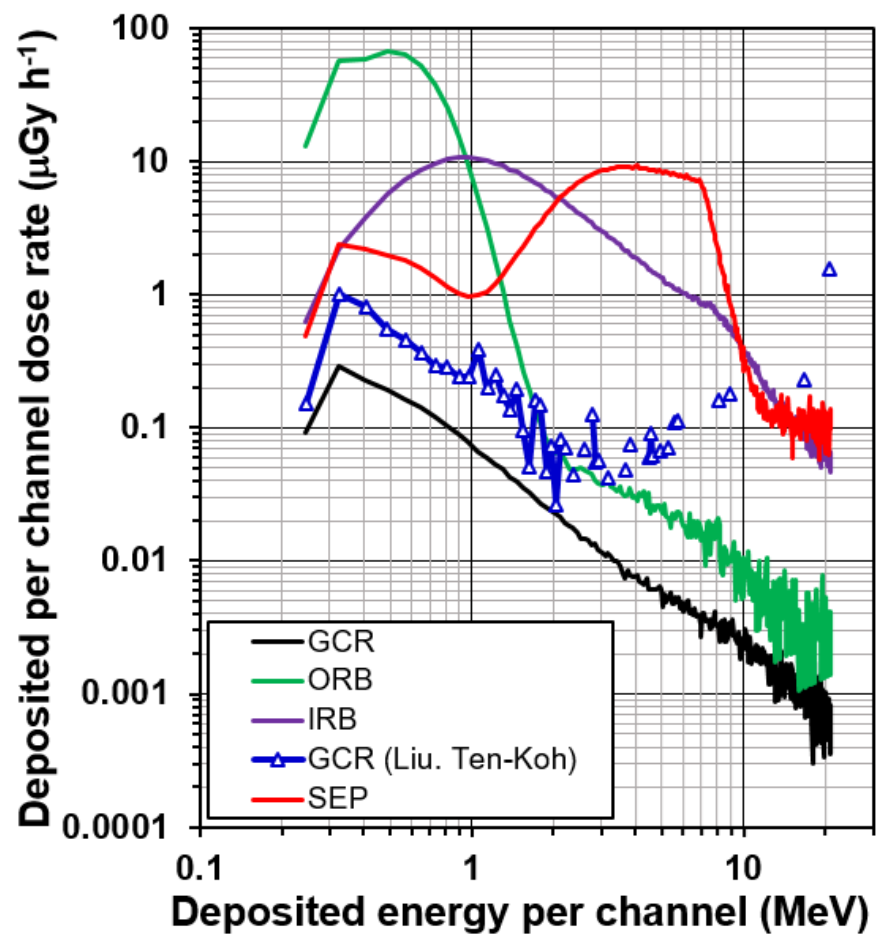

Fig. 9. Comparison of the "Liulin Ten-Koh Saganti" deposited energy spectrum shape with spectra, obtained on ISS with R3DR2 instrument for the period 21-30 June 2015

The "Liulin Ten-Koh Saganti" average spectrum is presented with blue triangles and lines. Nevertheless that, the values of this spectrum are higher than the GCR R3DR2 instrument spectrum (black line), the shape of this spectrum looks similar to the R3DR2 spectrum up to deposited energy of $3 \mathrm{MeV}$. Further, the Liulin Ten-Koh spectrum points, being only single points, depend strongly by the energy depositions in the channel (i.e. channel number) and their values are far above the R3DR2 instrument GCR spectrum values. Generally, the "Liulin TenKoh" spectrum is above the R3DR2 spectrum because

- The R3DR2 spectrum represents the global GCR dose rate, which is in average $2.78 \mu \mathrm{Gy} \mathrm{h}^{-1}$, while the Liulin Ten-Koh average spectrum represents only high latitude doses with an average value of $10.52 \mu \mathrm{Gy} \mathrm{h}^{-1}$. This is confirmed with the shape and position of the R3DR2 ORB spectrum above $3 \mathrm{MeV}$. This part of the ORB spectrum, obtained at high latitudes, contain GCR particles [15] that is why this part looks like natural continuation of the Liulin Ten-Koh average spectrum above $3 \mathrm{MeV}$; $(415 \mathrm{~km})$;

- The higher altitude of the Ten-Koh satellite $(\sim 620 \mathrm{~km})$ than ISS 
- The lover solar activity, which increases the GCR flux in the near Earth radiation environment. The small elevation of the first 2 points of the Liulin TenKoh spectrum can be interpreted as the presence of small, non-possible to distinguish, number of ORB relativistic electrons.

Using data from a rectangle with a-bit wider geographic region of BION-M No1 satellite [18], we calculate the end point L-coordinates of the 9 Ten-Koh satellite points. Fig. 10a shows the L-value [19] profile of the obtained 9 "Liulin Ten-Koh Saganti" dose rates and dose to flux (D/F) ratio.

Two variables are presented in Fig. 10a. The heavy red points present the measured dose rates, while the heavy blue points present the calculated dose to flux ratio. From previous experiments [15], we know that the D/F parameter could not fully characterise the type of predominant radiation source in the spectrum but can give significant information. The fact that the $\mathrm{D} / \mathrm{F}$ ratio in Fig. 10a have values close to $1 \mathrm{nGy} \mathrm{\textrm {cm } ^ { 2 }}$ particle ${ }^{-1}$ allow us to conclude that the predominant source are

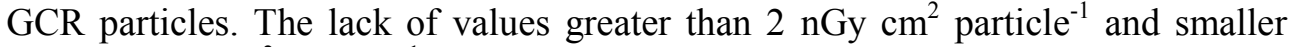
than $0.7 \mathrm{nGy} \mathrm{cm}^{2}$ particle $\mathrm{e}^{-1}$ allow us to conclude [15] that spectra with predominant IRB and ORB sources are not observed in the data. The comparison with the D/F data in Fig. 10b also confirms this conclusion.

Geomagnetic shielding [20] is the reason for reduced GCR dose rates of the first 2 points at low $\mathrm{L}$ values in Figure 10a and for the slightly rising dose rates towards $L$ values of 2.5. At these increasing $L$ values the vertical cut-off rigidity decreases, and the major number of low-energy GCR spectra penetrate down to the ten-Koh orbit. At higher $\mathrm{L}$ values, up to $\mathrm{L}=4.5$, the dose rate has fixed values because the small increase in the high-energy flux of the primary GCR flux does not affect it. The similarity of the polynomial asymptote (black curve) through the "Liulin Ten-Koh Saganti" dose rates shown in Fig. 10a with the moving average over 50 points black curve in Fig. $10 \mathrm{~b}$ also confirms the consideration that the observed 9 spectra contain mainly GCR source particles. As in Fig. 9 the "Liulin Ten-Koh Saganti" dose rates are higher even the R3DE dose rates, obtained at the previous solar minimum period in 2009. The reasons are the same as already discussed in the previous paragraphs.

As GCR pass through a target, many electromagnetic and nuclear interactions cause the incident particles to deposit some of their kinetic energy into the target material. The energy is deposited primarily in the form of ionisation of atoms in the target. The rate at which the incident particle deposits its energy in the target is termed linear energy transfer ( $\mathrm{LET}=-\mathrm{dE} / \mathrm{dx}$ ), energy deposited per unit path length) [21]. The LET spectrum and its evolution through the human body are essential ingredients in understanding and mitigating the potential radiation risk posed by energetic particles [22]. 


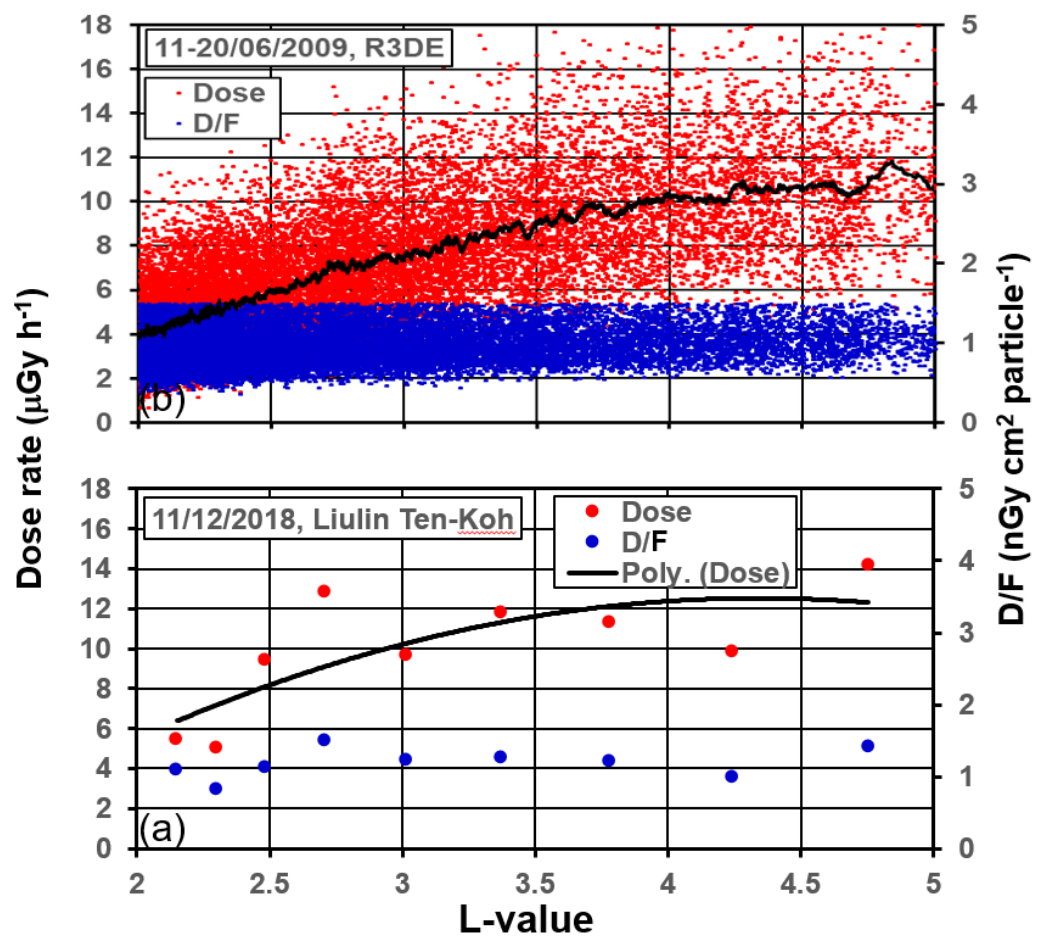

Fig. 10. Comparison of the L-Value profiles, obtained from the "Liulin Ten-Koh Saganti" spectrometer with R3DE data at ISS

Fig. 11 [23] compare:

- 2012-2013 silicon LET spectrum (large black points) from RAD instrument on Curiosity rower at the surface of Mars behind $21 \mathrm{~g} \mathrm{~cm}^{-2} \mathrm{CO}_{2}$ shielding;

- 2009-2011 silicon LET spectra from CRaTER instrument [24] on board the Lunar Reconnaissance Orbiter (LRO), which orbited the Moon in a $50 \mathrm{~km}$ (average) polar orbit with a period of about $100 \mathrm{~min}$. The data were obtained behind $0.2 \mathrm{~g} \mathrm{~cm}^{-2}$ (CRaTER D1/D2, small black points), $6 \mathrm{~g} \mathrm{~cm}^{-2}$ (CRaTER D3/D4, small red points), and $9 \mathrm{~g} \mathrm{~cm}^{-2}$ (CRaTER D5/D6, small blue points);

- 2008 silicon LET GCR spectrum (magenta points) from RADOM instrument [12], obtained behind $0.3 \mathrm{~g} \mathrm{~cm}^{-2}$ shielding in the interplanetary space between Earth and Moon in the period 29/10/2008 09:46:12-08/11/2008 00:00:00 UT. 52,687 10 s spectra were averaged;

- 2014-2016 silicon LET GCR global distribution spectrum (dark green points) from R3DR2 instrument, obtained behind $0.3 \mathrm{~g} \mathrm{~cm}^{-2}$ shielding. The spectrum was obtained by averaging 3,393,592 $10 \mathrm{~s}$ GCR spectra in the period 23/10/2014 10:31:43-10/01/2016 23:59:56 UT. 
- 2018 silicon LET GCR spectrum (blue triangles) from "Liulin Ten-Koh Saganti" instrument, obtained behind more than $0.3 \mathrm{~g} \mathrm{~cm}^{-2}$ shielding on 11 December 2018. The exact shielding is unknown but it is expected to be more than the self-shielding of the instrument because it is situated deeper in the construction of the Ten-Koh satellite and behind solar cell panel. The spectrum was obtained by averaging four 25.165824 s GCR spectra and five 29.61984 s spectra.

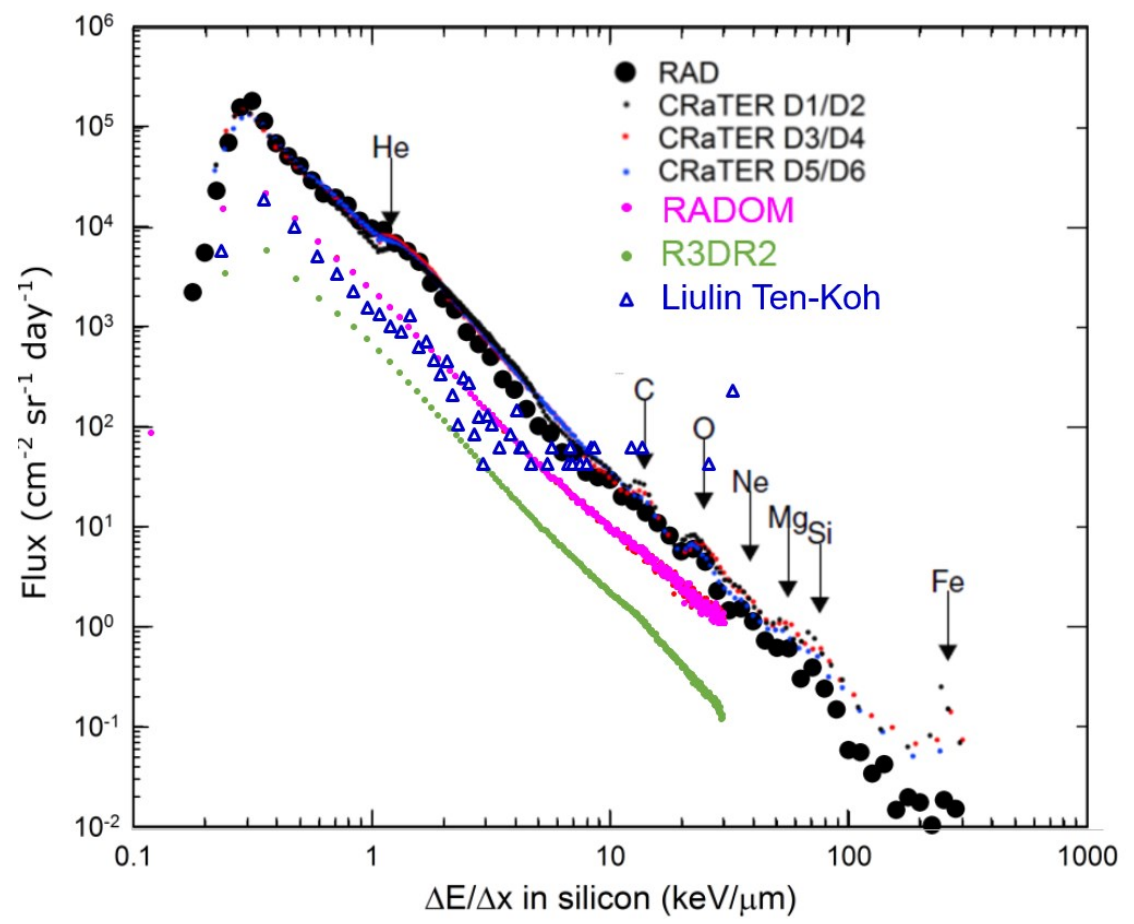

Fig. 11. Comparison of LET spectra, obtained by different instruments at different carriers inside and outside the Earth magnetosphere

Fig. 11 shows relatively good agreement between the shapes of the different spectra. The RADOM, R3DR2 and "Liulin Ten-Koh Saganti" spectra are shorter than the RAD and CRaTER spectra because they were obtained using single silicon detector, which covers only the LET range between 0.233 and $29.8 \mathrm{keV} \mu \mathrm{m}^{-1}$. These spectra include the energy depositions of $\mathrm{Neon}\left(\mathrm{Ne}^{+}\right)$ions as obtained by Dr Y. Uchihori [16] (see Fig. 11 there) but in Fig. 11, this is not seen, probably because unclear position of Neon maximum in the CRaTER spectra. The RADOM spectrum is below the RAD and CRaTER spectra because smaller shielding. The R3DR2 GCR spectrum is obtained inside the Earth magnetosphere and upper atmosphere that is why the number of CGR particles building the 
spectrum is smaller than the RAD, CRaTER and RADOM spectra. The "Liulin Ten-Koh Saganti" spectrum is a little bit below the RADOM spectrum because these data are obtained inside the magnetosphere in relatively small geographic region at middle latitudes.

\section{Conclusions}

This paper reveals that the authors and colleagues had successfully fulfilled the main task, i.e. to develop, construct and calibrate an engineering, flight, and operational models of a Liulin type particle spectrometer. After the standard sources radiation tests, which were performed during the calibrations, the flight model of the instrument was incorporated in the CPD instrument of Ten-Koh spacecraft. Nevertheless that the first amount of data from "Liulin Ten-Koh Saganti" spectrometer is relatively limited the comparisons show that they are correct and can be used for further analysis of the LEO environment.

\section{References}

1. Cucinotta, F. A, M. R. Shavers, P. Saganti, and J. Miller, Radiation Protection Studies of International, Space Station Extravehicular Activity Space Suits, NASA/TP-2003212051. https://ntrs.nasa.gov/archive/nasa/casi.ntrs.nasa.gov/20040031719.pdf.

2. Cucinotta, F. A., Cacao, E., Kim, M. H. Y., and Saganti, P. B., Cancer and circulatory disease risks for a human mission to Mars: Private mission considerations. Acta Astronautica, 2018. https://doi.org/10.1016/j.actaastro.2018.08.022.

3. Dachev, Ts., B. Tomov, Yu. Matviichuk, Pl. Dimitrov, J. Lemaire, Gh. Gregoire, M. Cyamukungu, H. Schmitz, K. Fujitaka, Y. Uchihori, H. Kitamura, G. Reitz, R. Beaujean, V. Petrov, V. Shurshakov, V. Benghin, F. Spurny, Calibration Results Obtained With Liulin-4 Type Dosimeters. Adv. Space Res. 2002, 30, 4, 917-25. http://dx.doi.org/10.1016/S0273-1177(02)00411-8.

4. Reitz, G., R. Beaujean, E. Benton, S. Burmeister, Ts. Dachev, S. Deme, M. LuszikBhadra, and P. Olko, Space radiation measurements on-board ISS-the DOSMAP experiment. Radiat Prot Dosimetry. 2005, 116, 374-79. http://rpd.oxfordjournals. org/cgi/content/abstract/116/1-4/374.

5. Nealy, J. E., F. A. Cucinotta, J. W. Wilson, F. F. Badavi, N. Zapp, T. Dachev, B. T. Tomov, E. Semones, S. A. Walker, G. de Angelis, S. R. Blattnig, and W. Atwell, Pre-engineering spaceflight validation of environmental models and the 2005 HZETRN simulation code, Adv. Space Res., 2007, 40, 11, 1593-1610. http://dx.doi.org/10.1016/j.asr.2006.12.030.

6. Wilson, J. W., J. E. Nealy, T. Dachev, B. T. Tomov, F. A. Cucinotta, F. F. Badavi, G. de Angelis, N. Leutke, and W. Atwell, Time serial analysis of the induced LEO environment within the ISS 6A, Adv. Space Res., 2007, 40, 11, 1562-70. http://dx.doi.org/10.1016/j.asr.2006.12.030. 
7. Slaba, T. C., S. R. Blattnig, F. F. Badavi, N. N. Stoffle, R. D. Rutledge, K. T. Lee, E. N. Zappe, T.P. Dachev, and B.T. Tomov, Statistical Validation of HZETRN as a Function of Vertical Cutoff Rigidity using ISS Measurements, Adv. Space Res., 2011, 47, 600-10. http://dx.doi.org/10.1016/j.asr.2010.10.021

8. Badavi, F. F., Validation of the new trapped environment AE9/AP9/SPM at low Earth orbit. Adv. Space Res. 2014, 54, 917-28. DOI:10.1016/j.asr. 2014.05.010.

9. Dachev, T. P., J. V. Semkova, B. T. Tomov, Yu. N. Matviichuk, Pl. G. S. Maltchev, R. Koleva, Pl., Dimitrov, N. G. Bankov, V. V., Shurshakov, V. V., Benghin, E. N., Yarmanova, O. A. Ivanova, D.-P. Häder, M. T. Schuster, G. Reitz, G. Horneck, Y. Uchihori, H. Kitamura, O. Ploc, J. Kubancak, and I. Nikolaev, Overview of the Liulin type instruments for space radiation measurement and their scientific results, 2015, 92-114. http://dx.doi.org/10.1016/j.lssr.2015.01.005.

10. Häder, D. P., P. Richter, M. Schuster, Ts. Dachev, B. Tomov, Pl. Georgiev, and $\mathrm{Yu}$. Matviichuk, R3D-B2 - Measurement of ionizing and solar radiation in open space in the BIOPAN 5 facility outside the FOTON M2 satellite, Adv. Space Res. 2009, 43, 8, 1200-11. http://dx.doi.org/10.1016/j.asr. 2009.01.021.

11. Damasso, M., Ts. Dachev, G. Falzetta, Giardi M. T., Rea G., and Zanini A., The radiation environment observed by Liulin-Photo and R3D-B3 spectrum-dosimeters inside and outside Foton-M3 spacecraft, Radiation Measurements, 2009, 44, 3, 263-72. http://dx.doi.org/10.1016/j.radmeas.2009.03.007.

12. Dachev, Ts. P., B. T. Tomov, Yu. N. Matviichuk, Pl .G. Dimitrov, Vadawale, S. V., J. N. Goswami, V. Girish, and G. de Angelis, An overview of RADOM results for Earth and Moon Radiation Environment on Chandrayyan-1 Satellite, Adv. Space Res., 2011, 48, 5, and 779-91. http://dx.doi.org/10.1016/j.asr.2011.05.009.

13. Dachev, Ts., G. Horneck, D.-P. Häder, M. Lebert, P. Richter, M. Schuster, and R. Demets, Time profile of cosmic radiation exposure during the EXPOSE-E mission: the R3D instrument. Journal of Astrobiology, 2012, 12, 5, 403-11. http://eea.spaceflight.esa.int/attachments/spacestations/ID501800a9c26c2.pdf.

14. Dachev, Ts., G. Horneck, D.-P. Häder, M. Schuster, and M. Lebert, EXPOSE-R cosmic radiation time profile, Journal of Astrobiology, 2015, 14, 17-25. http://dx.doi.org/ 10.1017/S1473550414000093.

15. Dachev, T. P., Bankov, N. G., Tomov, B. T., Matviichuk, Y. N., Dimitrov, P. G., Häder, D.-P., and Horneck, G. Overview of the ISS radiation environment observed during the ESA EXPOSE-R2 mission in 2014-2016. Space Weather, 2017, 15, 1475-89. https://doi.org/10.1002/2016SW001580.

16. Uchihori, Y., H. Kitamura, K. Fujitaka, Ts. P. Dachev, B. T. Tomov, P. G. Dimitrov, and Y. Matviichuk, Analysis of the calibration results obtained with Liulin-4J spectrometer-dosimeter on protons and heavy ions, Radiation Measurements, 2002, 35, 127-34. http://dx.doi.org/10.1016/S1350-4487(01)00286-4

17. Dachev, Ts., Characterization of near Earth radiation environment by Liulin type instruments, Adv. Space Res., 2009, 44, 1441-49. DOI:10.1016/ j.asr.2009.08.007

18. Dachev, Ts., B. Tomov, Yu. Matviichuk, Pl. Dimitrov, N. Bankov, V. Shurshakov, O. Ivanova, D.-P. Häder, M. T. Schuster, G. Reitz, and G. Horneck, "BION-M" №1 spacecraft radiation environment as observed by the RD3-B3 radiometerdosimeter in April-May 2013, Journal of Atmospheric and Solar-Terrestrial Physics. 2015, 123, 82-91. http://dx.doi.org/10.1016/j.jastp.2014.12.011 
19. McIlwain, C. E. Coordinates for mapping the distribution of magnetically trapped particles. Journal of Geophysical Research, 1961, 66, 3681-91. https://doi.org/ 10.1029/JZ066i011p03681

20. Shea, M. A., Smart, D. F., Gentile, and L.C., The use of the McIlwain L-parameter to estimate cosmic ray vertical cutoff rigidities for different epochs of the geomagnetic field. In NASA. Goddard Space Flight Center 19th Intern. Cosmic Ray Conf. 1985, 5, 332-35. http://articles.adsabs. harvard.edu// full/1985icrc...5..332s/E000332.000.htmlSimpson

21. Case, A.W., J. C. Kasper, H. E. Spence, C. J. Zeitlin, M. D. Looper, M. J. Golightly, N. A. Schwadron, L. W. Townsend, J. E. Mazur, J. B. Blake, and Y. Iwata., The deep space galactic cosmic ray lineal energy spectrum at solar minimum, Space Weather, 2013, 11, 361-68. doi:10.1002/swe.20051

22. Cucinotta, F. A., and M. Durante. Cancer risk from exposure to galactic cosmic rays: Implications for space exploration by human beings, The Lancet Oncology, 7, 2006. doi:10.1016/S1470-2045(06)70695-

23. Zeitlin, C., Results from the MSL-RAD Experiment on the Curiosity Mars Rover, Nineteenth WRMISS, Krakow, Poland, 9-11 September 2014. http://wrmiss.org/ workshops/nineteenth/Zeitlin_MSL-RAD.pdf

24. Chin, G., Brylow, S., Foote, M. et al., Lunar reconnaissance orbiter overview: The instrument suite and mission. Space Science Reviews, 2007, 129, 4, 391-419. https://doi.org/10.1007/s11214-007-9153-y

\title{
ОПИСАНИЕ НА СПЕКТРОМЕТЬРА НА ЗАРЕДЕНИ ЧАСТИЦИ "LIULIN TEN-KOH" ЗА ЯПОНСКИЯ СПЪТНИК "ТЕN-КОН"
}

\author{
Ц. Дачев, П. Димитров, Б. Томов, Ю. Матвийчук, П. Саганти, \\ Д. Холанд, К.-И. Окуяма
}

\section{Резюме}

На 29 октомври 2018 г. в 13:08 часа по японско стандартно време успешно беше изстрелян в орбита спьтника за наблюдение на парникови газове (GOSAT-2) от космическия център на JAXA Tanegashima. Заедно със спътника GOSAT-2 в кръгова (623 км) полярна синхронна орбита стартира и 22 килограмовият спьтник Ten-Koh (http://kit-okuyama-lab.com/en/ten-koh/, разработен в Kyushu Institute of Technology от проф. К. Окуяма. Ten-Koh ще наблюдава околоземното пространство и основната цел е да се осигурят данни за бъдещо развитие на спътниците и на тяхната работа. Основният научен експеримент на спътника Ten-Koh е Детектор за заредени частици (ДЗЧ), разработен в университета Prairie View A\&M, Тексас, САЩ и Джонсъновият космическия център на НАСА. Главен изследовател на експеримента е проф. П. Саганти (https://www.pvamu.edu/raise/space-payload/ charged-particle-detector-2018). Отговорен инженер е Д. Холанд. ИКИТ-БАН 
получи искане от проф. Саганти за разработване на инструмент от типа „Люлин“, който да бъде част от ДЗЧ. Учени от секцията по „Сльнчево и земна физика“" на ИКИТ разработиха и предадоха на университета Prairie View A\&M технологичен, летателен и резервен модели на инструмента "Liulin Ten-Koh". Последният е подобен на прибора RADOM, който работи през 2008-2009 г. на индийския спътник на луната Chadrayaan-1. Тази статия описва прибора "Liulin Ten-Koh" и тестовете със стандартни радиационни източници, които са проведени по време на калибровките. Спътникът TenKoh e на полярна орбита на около 623 километра надморска височина и наклон на орбитата от $98^{\circ}$. Получени са стабилни телеметрични данни от няколко наземни станции по целия свят. В статията са представени и първите получени данни от инструмента "Liulin Ten-Koh Saganti" на космическия кораб Ten-Koh. Наличният до този момент интегрален LET спектьр от прибора "Люлин Ten-Koh Saganti" е сравнен със спектри от други прибори, измерени във и извън земната магнитосфера. 